\title{
Entomopatógenos e óleo de nim associados a silício no manejo de tripes e míldio e rendimento de cebola
}

\author{
Paulo Antonio de Souza Gonçalves ${ }^{1}$ e Edivânio Rodrigues de Araújo²
}

\begin{abstract}
Resumo - O objetivo desse estudo foi avaliar entomopatógenos e óleo de nim associados a silício no manejo de tripes, míldio e variáveis de rendimento em cebola. O experimento foi conduzido na Empresa de Pesquisa Agropecuária e Extensão Rural de Santa Catarina (Epagri), Estação Experimental de Ituporanga. O transplantio e a colheita de bulbos se deram respectivamente em 17 de agosto e 7 de dezembro de 2015. Os tratamentos foram: Serenade (Bacillus subtilis) 1\%; Metiê ${ }^{\circ}$ (Metarhizium anisopliae) 1\%; Ballveria (Beauveria bassiana) 1\%; Fortneem (óleo de nim com 0,12\% p/p de azadiractina) 1\%, utilizados isoladamente ou associados a Bugran (terra de diatomáceas, composto por $98,58 \%$ de $\mathrm{SiO}_{2}$ ), e testemunha sem aplicação de tratamentos. Os tratamentos nas dosagens utilizadas, independentemente da adição de silício, não apresentaram efeito no manejo de tripes, míldio e na produtividade de cebola.
\end{abstract}

Termos para indexação: Allium cepa; Thrips tabaci; Peronospora destructor; Azadirachta indica; controle biológico.

\section{Entomopathogens and neem oil associated with silicon on the management of thrips, downy mildew and yield of onion}

\begin{abstract}
The objective of this study was to evaluate entomopathogens and neem oil associated with silicon on the management of thrips, downy mildew and onion yield variables. The experiment was carried out at Epagri, Ituporanga Experimental Station, Santa Catarina State, Brazil. The transplanting and harvesting of bulbs were performed respectively on 08/17/2015 and 12/07/2015. The treatments were: Serenade (Bacillus subtilis) 1\%; Metiê" (Metarhizium anisopliae) 1\%; Ballveria" (Beauveria bassiana) $1 \%$; Fortneem ${ }^{\circ}(0.12 \% \mathrm{w} / \mathrm{w}$ azadirachtin oil) $1 \%$, used alone or associated with Bugran (diatomaceous earth, composed of $98.58 \% \mathrm{SiO}_{2}$ ) and control without application. The treatments and dosages used, independently of the addition of silicon, had no effect on the management of thrips, downy mildew and yield of onion.
\end{abstract}

Index terms: Allium cepa; Thrips tabaci; Peronospora destructor; Azadirachta indica; biological control.

Os principais alvos no manejo fitossanitário de cebola no Sul do país, na fase de lavoura, são o míldio, causado pelo oomiceto Peronospora destructor (Berk.) Casp. (Peronosporales: Peronosporaceae) (Figura 1), e o inseto tripes, Thrips tabaci Lindeman 1888 (Thysanoptera: Thripidae) (Figura 2) (GONÇALVES, 2016; MARCUZZO \& ARAÚJO, 2016).

Os danos causados por tripes em cebola podem ocorrer em altas infestações, pela raspagem das folhas e sucção de seiva das plantas (GONÇALVES, 2016). As plantas danificadas apresentam lesões esbranquiçadas e redução de área foliar fotossintética, o que pode reduzir o tamanho e peso dos bulbos (GONÇALVES, 2016). A alta densidade populacional do inseto inibe o tombamento natural das folhas na maturação, o que facilita a entrada de água da chuva até os bulbos, causando perdas na armazenagem por apodrecimento (GONÇALVES, 2016).

O míldio constitui uma das principais doenças da cultura da cebola do Sul do Brasil, com riscos de perdas tanto na fase de canteiro como na lavoura em pós-transplante (MARCUZZO \& ARAÚJO, 2016). A ocorrência do míldio tem sido correlacionada a condições climáticas de temperaturas amenas e alta umidade relativa do ar (MARCUZZO \& ARAÚJO, 2016). A esporulação de míldio é noturna, com umidade relativa acima de $95 \%$ e temperaturas entre $4^{\circ} \mathrm{C}$ a $24^{\circ} \mathrm{C}$ (EMPRESA DE PESQUISA AGRO-
PECUÁRIA E EXTENSÃO RURAL DE SANTA CATARINA, 2013).

A bactéria Bacillus subtilis é aplicada no manejo de doenças de plantas e também pode atuar no controle de insetos devido à produção da toxina thuringiensina (PINTO et al., 2010).

Alguns fungos entomopatogênicos têm sido relatados com eficácia sobre o controle de T. tabaci em bioensaios, como Beauveria bassiana (HEMALATHA et al., 2014), e Metharhizium anisopliae em ambiente protegido (POURIAN et al., 2011). Em pesquisa de campo, $B$. bassiana tem apresentado maior eficácia que M. anisopliae (SHIBERU et al., 2013).

O nim, Azadirachta indica A. Juss (Meliaceae), é uma planta com efeito 


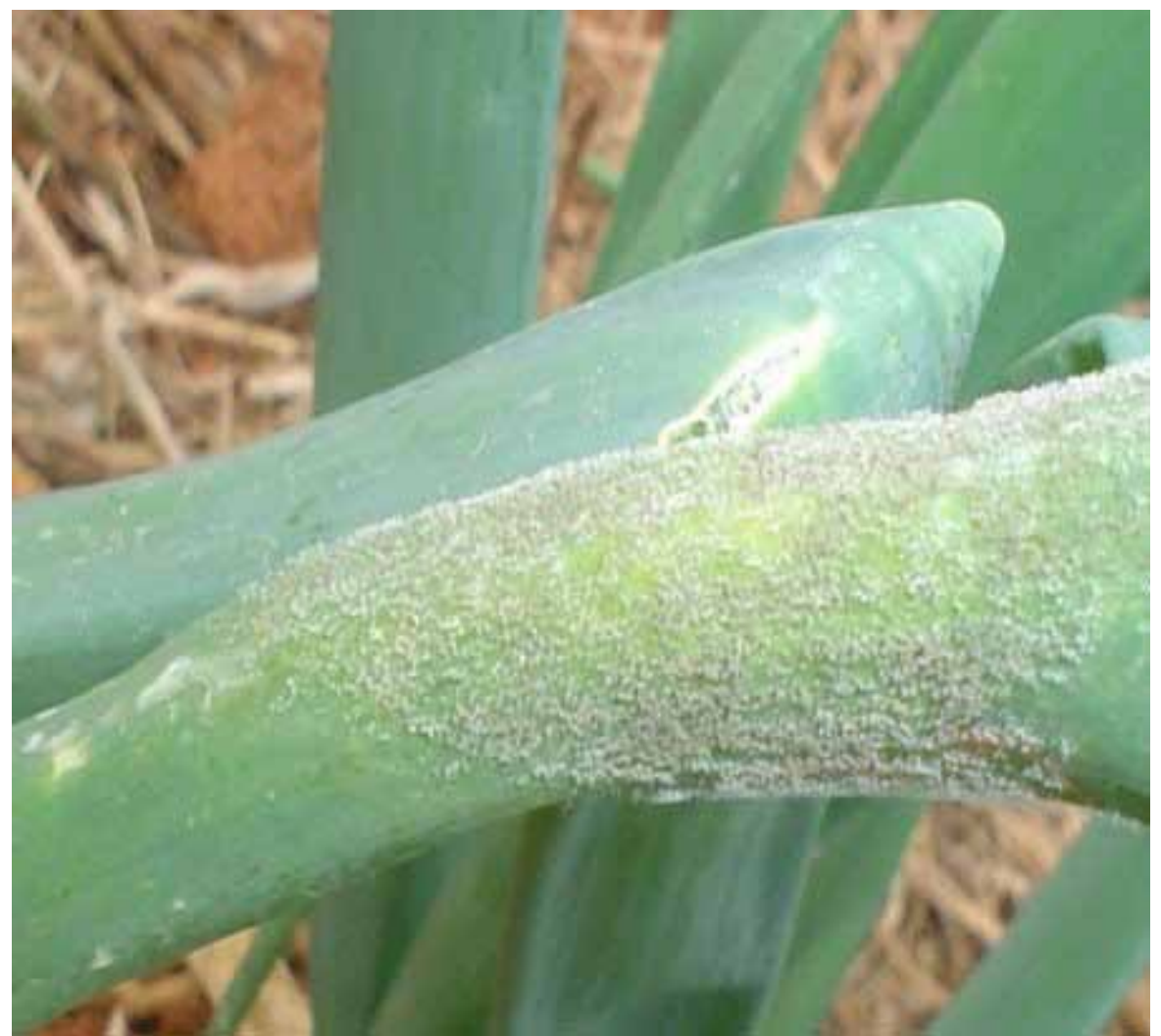

Figura 1. Folha de cebola infectada por míldio

Figure 1. Onion leaf infected by mildew

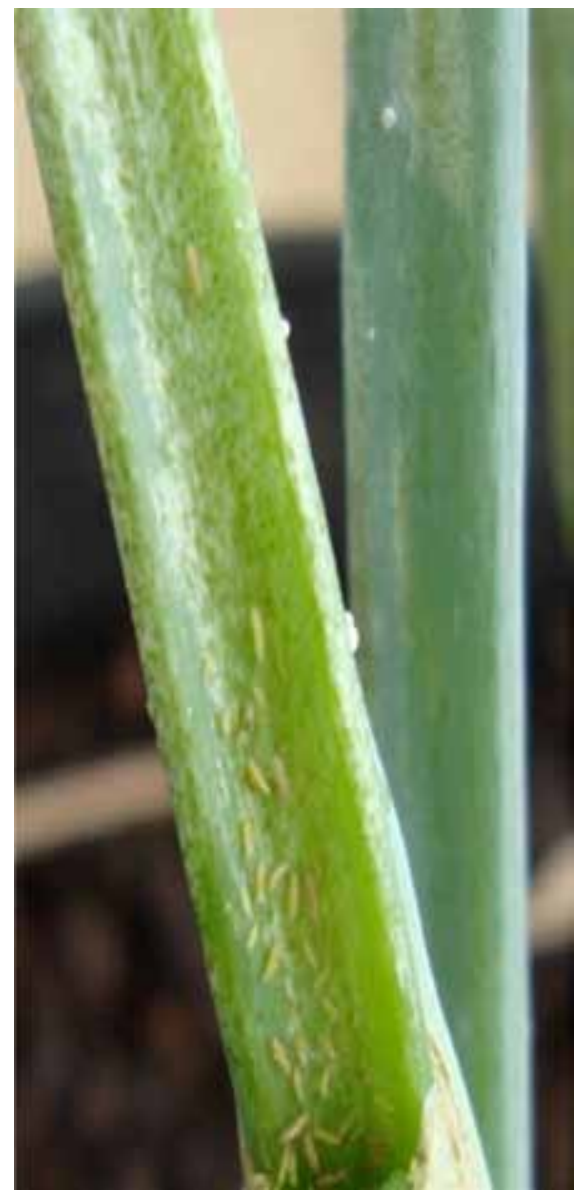

Figura 2. Folha de cebola com ninfas de tripes Figure 2. Onion leaf with thrips nymphs inseticida muito utilizada pelo baixo impacto ambiental (DEBASHRI \& TAMAL, 2012). Os extratos de sementes de nim reduziram a incidência de $T$. tabaci quando administrados em doses entre 2,5\% a 3\% (SHIBERU et al., 2013).

O silício é considerado um potencializador de resistência em plantas, devido à barreira mecânica que se forma nos tecidos pelo acúmulo deste mineral, além do incremento de compostos secundários que podem afetar o desenvolvimento de insetos e patógenos (ALCANTRA et al., 2010; GUERRA et al., 2013).

O objetivo desse estudo foi avaliar o efeito de entomopatógenos e óleo de nim associados a silício no manejo de tripes, míldio e em variáveis de rendimento em cebola.

O experimento foi conduzido na Empresa de Pesquisa Agropecuária e Extensão Rural de Santa Catarina (Epagri), Estação Experimental de Ituporanga, Santa Catarina, a $475 \mathrm{~m}$ de altitude, $27^{\circ} 22^{\prime} \mathrm{S}$ de latitude e $49^{\circ} 35^{\prime} \mathrm{W}$ de longitude, em cambissolo húmico distrófico. O cultivar utilizado foi 'Epagri 362 Crioula Alto Vale'. O transplantio e a colheita de bulbos foram realizados respectiva- mente em 17 de agosto e 7 de dezembro de 2015. O transplantio de mudas foi efetuado em canteiros no espaçamento de $0,2 \mathrm{~m}$ entre linhas e $0,1 \mathrm{~m}$ entre plantas, com população aproximada de 500.000 plantas por ha-1. 0 tamanho das parcelas experimentais foi de $3 \mathrm{~m}^{2}$, com cinco linhas de $3 \mathrm{~m}$ e $0,5 \mathrm{~m}$ de isolamento entre parcelas, com a área útil composta pelas três linhas centrais da parcela. A adubação na base do canteiro foi de $40 \mathrm{~kg}$ de $\mathrm{N} \mathrm{ha}^{-1}, 160 \mathrm{~kg}$ de $\mathrm{P}_{2} \mathrm{O}_{5}$ ha $^{-1}$ e $80 \mathrm{~kg}$ de $\mathrm{K}_{2} \mathrm{O} \mathrm{ha}{ }^{-1}$, e a fonte utilizada foi a fórmula NPK 5-20-10. A adubação de cobertura foi realizada com nitrogênio fornecido por ureia, nas doses de $52 \mathrm{~kg}$ de $\mathrm{N} \mathrm{ha}^{-1}$ aos 36 e 72 dias após transplante (DAT) e $36 \mathrm{~kg}$ de $\mathrm{N} \mathrm{ha}^{-1}$ aos 88 DAT.

Os tratamentos foram os produtos Serenade ${ }^{\circ}$ (Bacillus subtilis) $1 \%$; Metiê ${ }^{\circ}$ (Metarhizium anisopliae) 1\%; Ballveria ${ }^{\circ}$ (Beauveria bassiana) 1\%; Fortneem ${ }^{\circ}$ (óleo de nim com $0,12 \% \mathrm{p} / \mathrm{p}$ de azadiractina) $1 \%$, utilizados isoladamente ou associados a Bugran (terra de diatomáceas, composto por $98,58 \%$ de $\mathrm{SiO}_{2}$ ), além de testemunha sem aplicação de tratamentos. A linhagem de $B$. subtilis utilizada foi a QST $71313,68 \mathrm{~g} \mathrm{~L}^{-1} \mathrm{com}$ mínimo de $1 \times 10^{9}$ UFC (Unidade Formadora de Colônia) $\mathrm{g}^{-1}$ de ativo. $\mathrm{O}$ isolado de M. anisopliae foi o IBCB $425300 \mathrm{~g}$ $\mathrm{kg}^{-1}$ com $8 \times 10^{9} \mathrm{~g}^{-1}$ UFC. O isolado de $B$. bassiana foi o IBCB $66300 \mathrm{~g} \mathrm{~kg}^{-1} \mathrm{com}$ $1 \times 10^{9} \mathrm{~g}^{-1} \mathrm{UFC}$ por g de produto. O delineamento experimental foi o de blocos ao acaso com quatro repetições.

A pulverização foliar foi realizada com equipamento manual Guarany", com ponta de pulverização tipo cone, com pressão de 20,7 bar (300p.s.i), e volume de calda de $600 \mathrm{~L} \mathrm{ha}^{-1}$.

A incidência de tripes foi avaliada em cinco plantas ao acaso por parcela 24 horas após as pulverizações dos tratamentos. As avaliações de incidência de tripes foram realizadas durante a fase de formação de folhas até a bulbificação final aos 51, 59, 72, 87 e 93 DAT. Nesta avaliação foi utilizada escala de notas de incidência de acordo com os níveis populacionais de ninfas, sendo (0) ausência de ninfas); (1) até seis ninfas; (3) até 15 ninfas (considerado nível de dano econômico); (9) população $\geq 20$ ninfas (GONÇALVES et al., 2017).

Os danos de tripes foram avaliados em cinco plantas por parcela no final 
do ciclo, aos 99 DAT. Nesta avaliação foi adotada uma escala de danos foliares causados pelo inseto de acordo com o nível de lesões esbranquiçadas nas duas faces da planta, determinado pelas seguintes notas: (1) baixo; (3) médio (considerado como o nível de dano econômico); e (9) alto (GONÇALVES et al., 2018).

A quantificação da severidade do míldio se iniciou na fase de formação de folhas aos 55 DAT, desde o início da infestação. As avaliações foram semanais, num total de seis avaliações. Para quantificação da severidade utilizou-se uma escala descritiva (MOHIBULLAH, 1992) adaptada para a atribuição de notas e estimativa de severidade por parcela experimental. Desta forma, foi estabelecida a seguinte correlação (nota) e porcentagem de área foliar lesionada por míldio: (1) 0\%, sem sintomas; (2) $1 \%$, apenas algumas folhas atacadas; (3) $5 \%$, aproximadamente $25 \%$ do total de plantas da parcela atacadas; (4) $10 \%$, mais de $50 \%$ das plantas atacadas, ataque restrito a uma folha por planta; (5) $20 \%$, todas as plantas atacadas, ataque em uma ou duas folhas por planta; (6) $50 \%$, todas as plantas atacadas, três a quatro folhas por planta, parcela ainda mantém uma boa coloração verde; (7) $75 \%$, todas as folhas atacadas, parcela apresenta um aspecto inicial de queima das folhas; (8) $90 \%$, todas as folhas severamente atacadas, coloração verde restrita à parte central da parcela e/ou das plantas; (9) $100 \%$, todas as folhas completamente queimadas. Os valores das notas e respectivas severidades foram integralizados e calculados pela área abaixo da curva de progresso da doença (AACPD). O software GENES ${ }^{\circ}$ foi utilizado nas análises de variância para os dados de míldio.

A produtividade foi avaliada pela coIheita de todas as plantas da área útil da parcela. Os bulbos foram considerados comerciais quando apresentavam diâmetro igual ou superior a $50 \mathrm{~mm}$, sendo armazenados por cinco meses em caixas plásticas de $22 \mathrm{~kg}$, em galpão de madeira padrão utilizado pelos agricultores da região do Alto Vale do Itajaí, Santa Catarina. $O$ rendimento pós-colheita foi avaliado pelo descarte de bulbos podres por bacterioses e brotados. Os dados que apresentaram normalidade foram submetidos à análise de variância com o uso do programa SAS ${ }^{\circ}$ versão 6.12.

As notas médias de incidência $(2,5)$ e danos $(4,2)$ de tripes em cebola foram similares entre os tratamentos (Tabela 1). Isso difere da eficácia apontada para o uso de fungos entomopatógenos $B$. bassiana (SHIBERU et al., 2013; HEMALATHA et al., 2014) e Metharhizium spp. (POURIAN et al., 2011) no manejo de $T$. tabaci. A possibilidade de ação inseticida da toxina thuringiensina, oriunda de B. subtilis (PINTO et al., 2010), também não foi verificada. $O$ óleo de nim também não reduziu a incidência do inseto em contraste como estudo de Shiberu et al. (2013). Porém, em trabalho realizado no ano anterior no mesmo local, com dosagens indicadas pelas fabricantes desses produtos, sem a adição de silício no solo, também foi verificada a ineficácia desses tratamentos no manejo de tripes em cebola (GONÇALVES et al., 2018).

A AACPD média para a nota $(159,4)$ e para área foliar lesionada por míldio (799,5), correspondente a $75 \%$ de área foliar danificada na avaliação final, foi similar entre os tratamentos (Tabela 1). De maneira similar, os produtos avaliados sem uso do silício não apresentaram efeito no controle do míldio em campo, utilizando as dosagens recomendadas pelos fabricantes (GONÇALVES et al., 2018).

As variáveis de produtividade total, peso de bulbos e rendimento pós-coIheita não diferiram entre tratamentos (Tabela 1). Os dados da porcentagem de bulbos comerciais não apresentaram

Tabela 1. Notas da incidência (INC) e danos (DN) de Thrips tabaci por planta; área abaixo da curva de progresso da doença para nota de severidade (SEV) e para porcentagem de área foliar lesionada (AFL) do míldio (Peronospora destructor); porcentagem de bulbos comerciais (PC); produtividade total (PT em t ha-1); peso médio de bulbos (PB em g); porcentagem de rendimento pós-colheita (RPC) de cebola tratada com agentes de controle biológico e óleo de nim associados a silício. Empresa de Pesquisa Agropecuária e Extensão Rural de Santa Catarina (Epagri), Ituporanga, Santa Catarina, 2015

Table 1. Incidence (INC) and damage (DN) of Thrips tabaci per plant; area below the disease progression curve for severity score (SEV) and percentage of lesion leaf area (AFL) of mildew (Peronospora destructor); percentage of commercial bulbs (PC); total productivity (PT in tha ${ }^{-1}$ ); average weight of bulbs (PB in g); percentage of post-harvest yield (RPC) of onion treated with biological control agents and silicon-associated neem oil. Company of Agricultural Research and Rural Extension of Santa Catarina (Epagri), Ituporanga, Santa Catarina, 2015

\begin{tabular}{|c|c|c|c|c|c|c|c|c|}
\hline \multirow{2}{*}{ Tratamentos } & \multicolumn{8}{|c|}{ Médias } \\
\hline & INC & DN & SEV & AFL & PC & PT & PB & RPC \\
\hline BS & $2,9^{\text {ns }}$ & $5,6^{\mathrm{ns}}$ & $154,8^{\text {ns }}$ & $794,5^{\text {ns }}$ & 0,9 & $19,7^{\mathrm{ns}}$ & $39,4^{\text {ns }}$ & $74,5^{\mathrm{ns}}$ \\
\hline $\mathrm{BS}+\mathrm{TD}$ & 2,0 & 3,6 & 152,2 & 771,7 & 0,6 & 20,5 & 41,0 & 76,8 \\
\hline MA & 2,4 & 3,9 & 157,5 & 719,2 & 0,0 & 18,8 & 37,6 & 68,2 \\
\hline$M A+T D$ & 2,8 & 4,0 & 161,0 & 833,0 & 0,3 & 18,6 & 37,3 & 72,7 \\
\hline BB & 2,4 & 4,1 & 158,3 & 766,5 & 0,3 & 18,3 & 36,5 & 74,8 \\
\hline$B B+T D$ & 2,7 & 3,3 & 159,2 & 735,8 & 0,3 & 17,7 & 35,3 & 70,7 \\
\hline NIM & 2,7 & 3,9 & 167,1 & 861,8 & 0,0 & 18,9 & 37,8 & 69,2 \\
\hline NIM + TD & 2,2 & 4,9 & 164,5 & 894,2 & 0,0 & 17,7 & 35,4 & 69,1 \\
\hline Testemunha & 2,5 & 4,6 & 160,1 & 819,0 & 0,0 & 19,8 & 39,6 & 71,6 \\
\hline Média & 2,5 & 4,2 & 159,4 & 799,5 & 0,3 & 18,9 & 37,8 & 72,0 \\
\hline CV (\%) & 26,0 & 28,6 & 3,9 & 13,6 & 259,5 & 10,7 & 10,7 & 11,2 \\
\hline
\end{tabular}

NS, resultados não significativos a $5 \%$ de probabilidade pelo teste de F. BS, Bacillus subtilis. MA, Metarhizium anisopliae. BB, Beauveria bassiana. NIM, óleo de nim, todos aplicados na dose de $1 \%$ em pulverização foliar. TD, terra de diatomáceas aplicada na dose de 0,5\%. 
normalidade, portanto foram considerados apenas as médias e o coeficiente de variação (Tabela 1). A homogeneidade dessas variáveis foi relacionada à similaridade entre tratamentos no manejo de tripes e míldio. Os tratamentos avaliados na ausência da associação com silício também não influenciaram as variáveis de rendimento (GONÇALVES et al., 2018).

Os tratamentos nas dosagens utilizadas, independentemente da adição de silício, não apresentaram efeito no controle de tripes, míldio e na produtividade de cebola.

Os resultados, embora não significativos, são importantes para os agricultores e técnicos que trabalham com a cultura da cebola, pois os envolvidos com o setor da cebola poderão economizar em insumos e mão de obra ao não utilizar produtos comerciais que possuam as composições avaliadas.

\section{Agradecimentos}

À Fundação de Amparo à Pesquisa e Inovação do Estado de Santa Catarina (Fapesc).

\section{Referências}

ALCANTRA, E.; MORAES, J.C.; ANTÔNIO, A. Efeito de indutores da resistência e cultivares de algodão no comportamento de Aphis gossypii. Ciência Agronômica, Fortaleza, v.41, n.4, p.619-624, 2010.

DEBASHRI, M.; TAMAL, M. A review on efficacy of Azadirachta indica A. Juss based biopesticides: an Indian perspective. Research Journal of Recent Sciences, Indore, v.1, n.3, p.94-99, 2012.

EMPRESA DE PESQUISA AGROPECUÁRIA E EXTENSÃO RURAL DE SANTA CATARINA. Sistema de produção para a cebola: Santa Catarina. 4.ed. Florianópolis: Epagri, 2013.

GONÇALVES, P.A.S. Manejo de pragas. In: MENEZES JÚNIOR, F.O.G.; MARCUZZO, L.L. (Orgs.). Manual de boas práticas agrícolas: guia para a sustentabilidade das lavouras de cebola do estado de Santa Catarina. Florianópolis: Epagri, 2016. p.81-90.

GONÇALVES, P.A.S.; ALVES, D.P.; ARAÚJO, E.R. Incidência de tripes em genótipos de cebola. Revista Thema, Pelotas, v.14, n.2, p.286-297, 2017.

GONÇALVES, P.A.S.; ARAÚJO, E.R.; MENEZES JÚNIOR, F.O.G. Agentes de controle biológico, óleo de nim e fertilizantes foliares no manejo de tripes e míldio em cebola. Global Science and Technology, Rio Verde, v.11, n.1, p.58-66, 2018.

GUERRA, A.M.N.M.; RODRIGUES, F.A.; BERGER, P.G.; BARROS, A.F.; RODRIGUES, Y.C.; LIMA, T.C. Resistência do algodoeiro à ferrugem tropical potencializada pelo silício. Bragantia, Campinas, v.72, n.3, p.279-291, 2013.
HEMALATHA, S.; RAMARAJU, K.; JEYARANI, $S$. Evaluation of entomopathogenic fungi against tomato thrips, Thrips tabaci Lindeman. Journal of Biopesticides, Tamil Nadu, v.7, n.2, p.151-155, 2014.

MARCUZZO, L.L.; ARAÚJO, E.R. Manejo de doenças. In: MENEZES JÚNIOR, F.O.G.; MARCUZZO, L.L. (Orgs.). Manual de boas práticas agrícolas: guia para a sustentabilidade das lavouras de cebola do estado de Santa Catarina. Florianópolis: Epagri, 2016. p.91-111.

MOHIBULLAH, A. Studies on major diseases of bulb vegetables (onion and garlic) in NWFP. (Pakistan). Tarnab Peshawar: Agricultural Research Institute, 1992.

PINTO, L.M.N.; BERLITZ, D.L.; CASTILHOSFORTES, R.; FIUZA, L.M. Toxinas de Bacillus thuringiensis. Biotecnologia, Ciência e Desenvolvimento, Brasília, DF, v.11, n.38, p. 24-31, 2010.

POURIAN, H.R.; TALAEI-HASSANLOUI, R.; KOSARI, A.A.; ASHOURI, A. Effects of Metarhizium anisopliae on searching, feeding and predation by Orius albidipennis (Hem., Anthocoridae) on Thrips tabaci (Thy., Thripidae) larvae. Biocontrol Science and Technology, Abingdon, v.21, n.1, p.15-21, 2011.

SHIBERU, T.; NEGERI, M.; SELVARAJ, T. Evaluation of some botanicals and entomopathogenic fungi for the control of onion thrips (Thrips tabaci L.) in West Showa, Ethiopia. Journal of Plant Pathology \& Microbiology, Hyderabad, v.4, n.161, p.2-7, 2013.

\section{Avalie regularmente a qualidade da água que você consome.}

Laboratórios de Análises de Águas:

Fone : (49) 3328-4277

E-mail: cepaf@epagri.sc.gov.br Chapecó, SC

Fone: (48) 3465-1933

E-mail: eeur@epagri.sc.gov.br Urussanga, SC

Fone: (49) 3341-5244

E-mail: eei@epagri.sc.gov.br Itajai, SC 